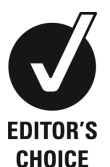

CHOICE

\title{
Breast pain in a patient on dialysis: a rare manifestation of calcific uraemic arteriolopathy
}

\author{
Konrad Buscher, ${ }^{1}$ Gert Gabriëls, ${ }^{1}$ Peter Barth, ${ }^{2}$ Hermann Pavenstädt ${ }^{1}$
}

${ }^{1}$ Department of Nephrology, University Clinic Muenster, Muenster, Germany ${ }^{2}$ Department of Pathology, University Clinic Muenster, Muenster, Germany

\section{Correspondence to}

Dr Konrad Buscher, konrad.buscher@ukmuenster.de

Accepted 25 December 2014

CrossMark

To cite: Buscher $K_{\text {, }}$ Gabriëls $G$, Barth $P$, et al. BMJ Case Rep Published online: [please include Day Month Year] doi:10.1136/ bcr-2014-207946

\section{SUMMARY}

A 63-year-old woman presented with progredient bilateral breast pain. Her medical history included rheumatoid arthritis, AA amyloidosis and end-stage renal disease treated by peritoneal dialysis. Inflamed skin alterations of the breast and laboratory values suggested mastitis non-puerpuralis but antibiotics did not resolve the symptoms. Sonography and mammography showed severe vessel calcification suggesting calcific uraemic arteriolopathy (calciphylaxis) as a rare complication of chronic kidney disease. Treatment included intensified haemodialysis, thiosulfate application, analgaesia and wound management leading to significant improvement, however, without complete remission.

\section{BACKGROUND}

This case of a rare manifestation of calciphylaxis solely in the breast shows the importance of thinking 'outside the box'. The pathologists, radiologists, gynaecologists and nephrologists involved had never before observed such a case. By literature research and discussing the case in an interdisciplinary manner, we achieved consensus about diagnosis and treatment. Early diagnosis was particularly essential to prevent more irreversible tissue damage due to necrosis. This case demonstrates that interdisciplinary communication greatly enhances the quality of medical treatment.

There is an increasing body of evidence suggesting sonography or mammography as equally sensitive diagnostic methods to detect vascular calcification compared to X-ray of peripherial vessels. Our findings also support that notion and add that the microcirculation of the breast can be even more severely affected than that of the extremities.

Invasive procedures such as biopsies can cause significant secondary complications that might overcome the benefits. Here, the wound caused by the biopsy subsequently got infected due to poor microcirculation and antibiotic treatment turned out to be ineffective. Since there are sensitive noninvasive diagnostics available, we would like to sensitise physicians to rethink the necessity of invasive procedures carefully.

\section{CASE PRESENTATION}

A 63-year-old Caucasian woman on peritoneal dialysis presented with progredient breast pain. Symptoms started 3-4 weeks prior with bilateral severe sharp pain and itching aggravated by movement. At the time, gynaecological consultation did not reveal signs of inflammation or malignancy.
The patient's medical history included years of obesity, arterial hypertension and rheumatoid arthritis with secondary AA amyloidosis causing chronic kidney disease (CKD) and secondary hyperparathyroidism. Peritoneal dialysis was initiated 1 year before presentation with a residual urine output of $700 \mathrm{~mL} /$ day. The weekly $\mathrm{Kt} / \mathrm{V}$ value calculated some weeks before admission was 2.2 (renal 0.4, PD 1.8) and the weekly creatinine clearance $53 \mathrm{~L}$ (renal 9, PD 44). Medication on admission included low-dose prednisolone, furosemide, xipamide, cholecalciferol, erythropoietin, pantoprazole, active vitamin D analogue, vitamin supplements, buprenorphine and metamizole. No warfarin or heparin was prescribed.

\section{INVESTIGATIONS}

Physical examination showed intense mastodynia, bilateral erythaema, induration and open wounds in the perimammillary area (figure 1), and moderate peripheral oedema. No enlarged lymph nodes were palpable. Blood test showed elevated phosphorus, creatinine, hypoalbuminaemia and an inadequate treatment of the secondary hyperparathyroidism. Markers for inflammation were elevated (table 1). Sonographic evaluation identified hypertrophic lymph nodes, dilated lymph vessels and mammary ducts. Numerous shadowing foci were detectable throughout the parenchyma (figure 2). These findings were further corroborated by mammography that showed extensive calcification of the entire vascular bed, but no other evidence for malignancy (figure 3). Histologically,

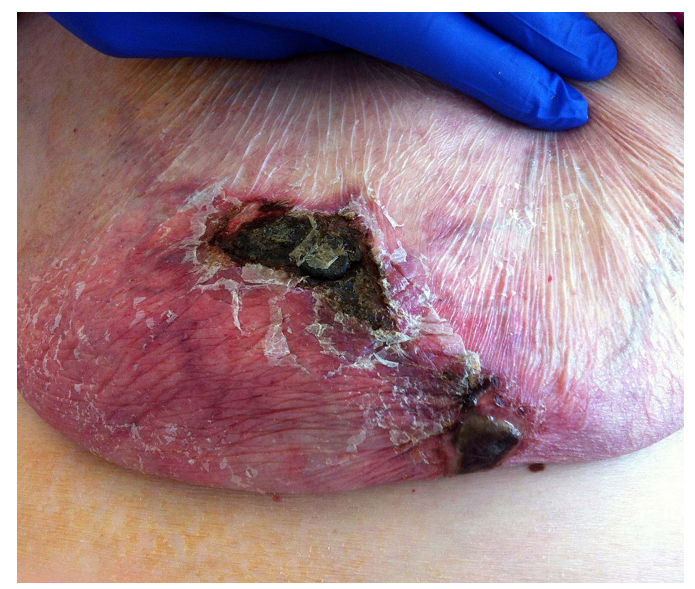

Figure 1 Photograph of the left breast showing perimammillary erythaema, purulent areas, necrosis and partial wound healing. Severe mastodynia was triggered by touch and movement. 
Table 1 Laboratory values on admission

\begin{tabular}{ll}
\hline Creatinine & $8.3 \mathrm{mg} / \mathrm{dL}(734 \mu \mathrm{mol} / \mathrm{L})$ \\
GFR & $5 \mathrm{~mL} / \mathrm{min} / 1.73 \mathrm{~m}^{2}$ (MDRD) \\
Urea & $42 \mathrm{mg} / \mathrm{dL}(7.0 \mathrm{mmol} / \mathrm{L})$ \\
Calcium & $1.6 \mathrm{mmol} / \mathrm{L}(7.2 \mathrm{mg} / \mathrm{dL})$ \\
Corrected calcium & $2.56 \mathrm{mmol} / \mathrm{L}(10.3 \mathrm{mg} / \mathrm{dL})$ \\
Phosphorus & $5.7 \mathrm{mmol} / \mathrm{L}(17.7 \mathrm{mg} / \mathrm{dL})$ \\
Albumin & $1.8 \mathrm{~g} / \mathrm{dL}$ \\
Parathyroid hormone & $364 \mathrm{pg} / \mathrm{mL}(38.6 \mathrm{pmol} / \mathrm{L})$ \\
WCC & $13.400 / \mu \mathrm{L}$ \\
CRP & $27.4 \mathrm{mg} / \mathrm{dL}(274 \mathrm{mg} / \mathrm{L})$ \\
Procalcitonin & $2.1 \mathrm{ng} / \mathrm{mL}$
\end{tabular}

CRP, C reactive protein; GFR, glomerular filtration rate; MDRD, modification of diet in renal disease; WCC, white cell count.

necrotic connective tissue with granular karyorrhectic debris, finely granular calcifications and a few necrotic glands were evident (figure 4). Iron staining was negative (not shown).

\section{DIFFERENTIAL DIAGNOSIS}

Clinical signs, elevated $\mathrm{C}$ reactive protein and procalcitonin serum levels suggested a non-puerperal mastitis. Inflammatory breast cancer, arterial embolisation and calcific uraemic arteriolopathy were also discussed.

\section{TREATMENT}

Antibiotics were administered, which partly resolved the bacterial infection but did not lead to substantial clinical amelioration or pain reduction. Sonography and mammography strongly argued for a manifestation of calcific uraemic arteriolopathy (calciphylaxis) solely in the breast. Histology of a punch biopsy did not show signs of malignancy. An interdisciplinary discussion with nephrologists, gynaecologists, radiologists and pathologists strongly favoured a conservative approach as any operative intervention is considered high risk due to impaired wound healing. This reasoning was further underlined by the fact that the skin wound of the biopsy later got infected as well.

Although the recent $\mathrm{Kt} / \mathrm{V}$ value of 2.2 indicated a good dialysis adequacy according to KDOQI guidelines, blood tests on admission (creatinine, phosphorus, albumin) suggested an ineffective dialysis regime. The main therapeutic goal was the improvement

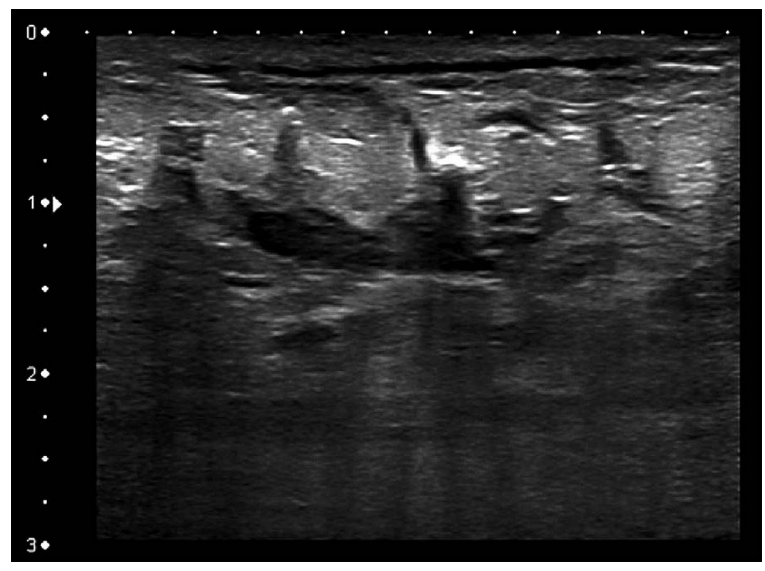

Figure 2 Breast sonography revealed hypertrophic lymph nodes, dilated lymph vessels and mammary ducts. Note diverse foci with a shadowing phenomenon indicating severe calcifications.

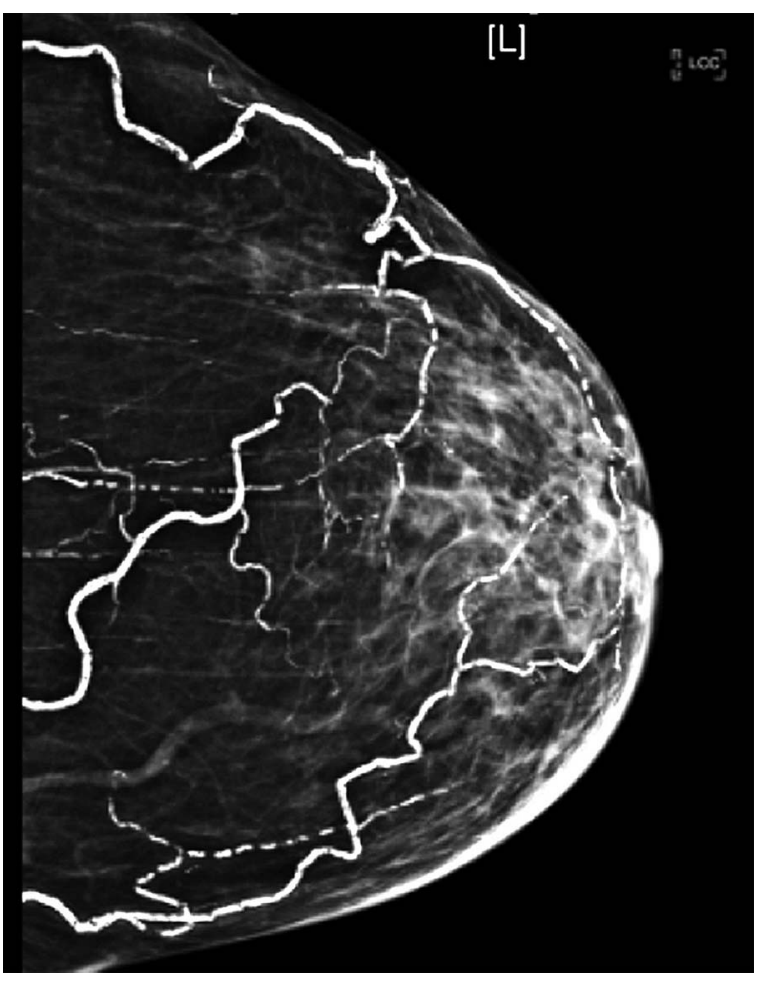

Figure 3 Mammogram of the left breast showing massive vascular calcifications. No masses or microcalcifications were observed as signs for malignancy.

of the calcium/phosphorus homoeostasis. In this case, we switched to daily haemodialysis using sodium thiosulfate $(25 \mathrm{~g}$ three times weekly), stopped triggering agents such as active vitamin D and calcium-containing phosphate binders, and optimised treatment of secondary hyperparathyroidism using sevelamer and cinacalcet. Analgaesia by NSAR and opioids was only partly sufficient. The additional prescription of pregabalin seemed beneficial. In cases such as this, gentle debridement of necrotic lesions may be required, particularly in large skin lesions.

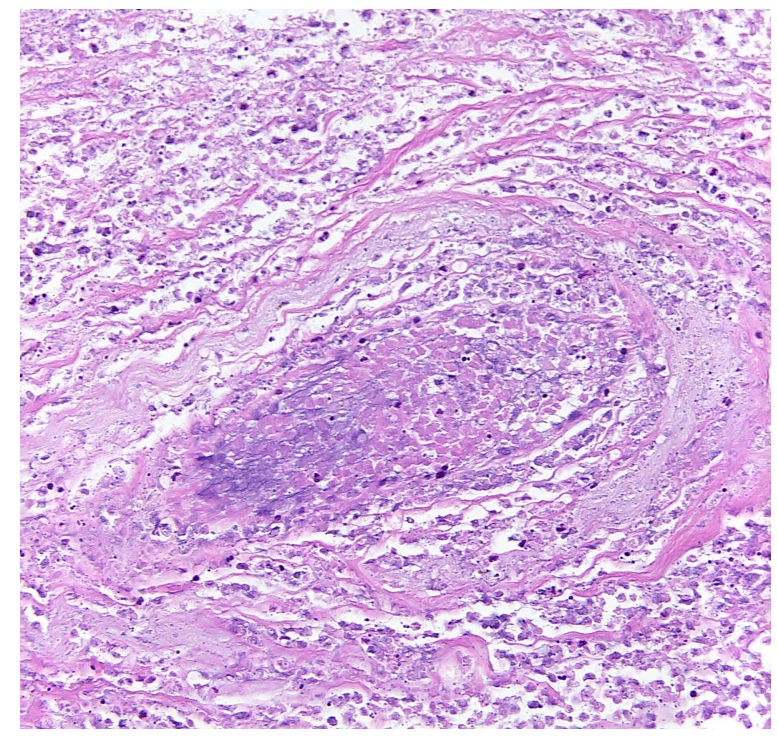

Figure 4 A skin biopsy of the affected perimammilar region of the right breast showing lymphangiectasia, focal calcium deposits and fat tissue necrosis. 
As no proteinuria, hepatic or intestinal pathologies were evident, severe hypoalbuminaemia was attributed to a combination of fluid excess and malnutrition. Haemodialysis with temporary intradialytic parenteral nutrition led to significant improvement.

\section{OUTCOME AND FOLLOW-UP}

By taking this multi-interventional approach, a significant amelioration was achieved within 4 weeks, however, without complete remission. Necrotic areas were prone to recurrent infection including the site of biopsy, and systemic and local antibiotic therapy was required. The calcium-phosphorus homoeostasis and skin lesions ameliorated, and the patient's quality of life improved significantly; further interventions were not necessary.

\section{DISCUSSION}

Severe calcific uraemic arteriolopathy is rare in patients with CKD. Owing to missing prospective, randomised studies, treatment regimes are not standarised yet and are mostly based on pathophysiological reasoning, retrospective analysis and individual case reports. While calcium-phosphorus homoeostasis is seen as a key factor of extraosseous calcification, more recent findings put forward the important role of endogenous inhibitors, debris clearance as well as lipids, uraemic toxins and systemic inflammation. ${ }^{1}$

Calcium deposition can occur in any tissue including, for example, internal organs ${ }^{2}$ and the aortic valve. ${ }^{3}$ The isolated affection of the breast is rare and emphasises that any skin alteration or body dysfunction in patients with CKD should be screened for calciphylaxis. This requires a close and fast interdisciplinary work up as potentially life-threatening conditions can result. $^{2}$

The damaged microcirculation impairs proper wound healing and is a major threat for any invasive procedures such as biopsies. ${ }^{4}$ Also, due to patchy calcification patterns, histology can be inconclusive. ${ }^{5}$ As regards the breast, we believe that sonography ${ }^{6}$ and mammography are sufficient for diagnosis in these patients. Therefore, depending on individual circumstances, we encourage critically reassessing the necessity of biopsies in these patients. However, in case of uncertainty, histology is required to differentiate between drug-induced skin necrosis (eg, warfarin, heparin), calciphylaxis and other skin disorders.

It is important to start early and aggressive conservative treatment to prevent progression of necrosis. Operative debridement or mastectomy are options after unsuccessful conservative handling, for example, antibiotic-resistant superinfection or increasing skin lesions. Although complete remissions after parathyroidectomy have been observed, other reports describe postoperative recurrence, ${ }^{7}$ and a review of 16 cases does not recommend it routinely. ${ }^{8}$ More detailed pathophysiological insights are needed to establish new therapeutical approaches.

This case shows a rare manifestation of calciphylaxis in the breast being sufficiently diagnosed by sonography and mammography. Interdisciplinary discussion yielded a reasonable therapy regime that eventually led to a significant increase in the patient's quality of life.

\section{Learning points}

- Calcific uraemic arteriolopathy is a rare complication of chronic kidney disease with unknown pathophysiology.

- It mostly presents as ulcerative skin lesions of the extremities, but other tissues or organs can also be affected.

- Sonography and plain radiography can be sufficient for diagnosis and a biopsy should be considered in case of uncertainty.

- Treatment includes improving the calcium/phosphorus homoeostasis, off-label use of thiosulfate, analgaesia and careful management of wound lesions.

\section{Acknowledgements The authors would like to thank Dr M Plaßmann for her} support.

Contributors KB, GG and HP were involved in drafting Treatment and Discussion section of the article. PB was involved in drafting Histology and Discussion section of the article.

\section{Competing interests None.}

\section{Patient consent Obtained.}

Provenance and peer review Not commissioned; externally peer reviewed.

\section{REFERENCES}

1 Ketteler $\mathrm{M}$, Rothe $\mathrm{H}$, Krüger $\mathrm{T}$, et al. Mechanisms and treatment of extraosseous calcification in chronic kidney disease. Nat Rev Nephrol 2011;7:509-16.

2 Volpini K, Kinonen C. Abdominal catastrophe in a 43-year-old female with end stage renal disease. Semin Dial 2011;24:79-82.

3 Asirvatham S, Sebastian C, Sivaram C, et al. Aortic valve involvement in calciphylaxis: uremic small artery disease with medial calcification and intimal hyperplasia. Am J Kidney Dis 1998;32:499-502.

4 Thornton JJ, Dolph J. Breast necrosis: calciphylaxis a rare cause. Can J Plast Surg 2008; 16:165-7.

5 Gupta D, Tadros R, Mazumdar A, et al. Breast lesions with intractable pain in end-stage renal disease: calciphylaxis with chronic hypotensive dermatopathy related watershed breast lesions. J Palliat Med 2013;16:551-4.

6 Bukhman R, Scheri RP, Selim MA, et al. Sonography in the identification of calciphylaxis of the breast. J Ultrasound Med 2010;29:129-33.

7 Katikaneni M, Lwin L, Villanueva $H$, et al. Calciphylaxis and subtotal parathyroidectomy: a double-edged sword. Hemodial Int 2013;17(Suppl 1):S33-6.

8 Kang AS, McCarthy JT, Rowland C, et al. Is calciphylaxis best treated surgically or medically? Surgery 2000;128:967-72.

Copyright 2015 BMJ Publishing Group. All rights reserved. For permission to reuse any of this content visit

http://group.bmi.com/group/rights-licensing/permissions.

BMJ Case Report Fellows may re-use this article for personal use and teaching without any further permission.

Become a Fellow of BMJ Case Reports today and you can:

- Submit as many cases as you like

- Enjoy fast sympathetic peer review and rapid publication of accepted articles

- Access all the published articles

- Re-use any of the published material for personal use and teaching without further permission

For information on Institutional Fellowships contact consortiasales@bmjgroup.com

Visit casereports.bmj.com for more articles like this and to become a Fellow 